\title{
Selection of Compositions with High Glass Forming Ability in the Ni-Nb-B Alloy System
}

\author{
Marcio Andreato Batista Mendes ${ }^{\mathrm{a} *}$, Luis César Rodríguez Aliaga ${ }^{\mathrm{b}}$, Claudio Shyinti Kiminami $^{\mathrm{b}}$, \\ Marcelo Falcão de Oliveirac, Walter José Botta ${ }^{\text {b }}$ Claudemiro Bolfarini ${ }^{\mathrm{b}}$
}

\author{
a Programa de Pós-graduação em Ciência e Engenharia de Materiais, Departamento de Engenharia de \\ Materiais, Universidade Federal de São Carlos - UFSCar, Rod. Washington Luis, \\ Km 235, CEP 13565-905, São Carlos, SP, Brasil \\ ${ }^{\mathrm{b}}$ Departamento de Engenharia de Materiais, Universidade Federal de São Carlos - UFSCar, \\ Rod. Washington Luis, Km 235, CEP 13565-905, São Carlos, SP, Brasil \\ ${ }^{\mathrm{c}}$ Departamento de Engenharia de Materiais, Aeronáutica e Automobilística, Universidade de São Paulo - USP, \\ Av. Trabalhador São-carlense, 400, CEP 13560-970, São Carlos, SP, Brasil
}

Received: November 11, 2011; Revised: May 10, 2012

\begin{abstract}
A combination of an extension of the topological instability " $\lambda$ criterion" and the "average electronegativity" has been recently reported in the literature to predict compositions with high glass-forming ability (GFA). In the present work, both criteria have been applied to select the $\mathrm{Ni}_{61.0} \mathrm{Nb}_{36.0} \mathrm{~B}_{3}$ alloy with a high glass-forming ability. Ingots were prepared by arc-melting and were used to produce ribbons processed by the melt-spinning technique further characterized by differential scanning calorimetry (DSC), X-ray diffraction (XRD) and scanning electron microscopy (SEM). The $\mathrm{Ni}_{61.0} \mathrm{Nb}_{36.0} \mathrm{~B}_{3}$ alloy revealed a complete amorphization and supercooled liquid region $\Delta \mathrm{T}_{\mathrm{x}}=68 \mathrm{~K}$. In addition, wedge-shaped samples were prepared using copper mold casting in order to determine the critical thickness for amorphous formation. Scanning electron microscopy (SEM) revealed that fully amorphous samples could be obtained, reaching up to $\sim 800 \mu \mathrm{m}$ in thickness.
\end{abstract}

Keywords: metallic glass, rapid solidification processing, ternary alloy systems

\section{Introduction}

The search for new bulk metallic glasses (BMG) has traditionally been guided by models and semi-empirical approximations in order to predict composition in a given system. In that context, it is worth noting these different empirical rules: the atomic mismatch, negative heat of mixing among the alloying elements, and alloys consisting of more than two elements, better known as the multicomponent effect ${ }^{1}$. The latter condition adds high complexity degree to the alloy according to the "confusion principle"2; thus, the supercooled melt leads to easy amorphous phase formation during rapid quenching.

The selection of good glass-former compositions is a crucial factor in the development of bulk metallic glasses. For forecasting compositions in the Ni-Nb-B ternary system with high glass-forming ability, we used the combination of two criteria: topological instability " $\lambda$ criterion" and the average electronegativity $\overline{\Delta e}$. The " $\lambda_{\text {min }}$ criterion", which is based on the concept of topological instability of a stable crystalline structure, was first proposed to justify the amorphization of binary solid solution alloys ${ }^{3}$. In the original criterion, the topological destabilization of a crystalline structure was associated with a critical solute concentration necessary to exceed the mean elastic volume strain in supersaturated solid solutions. A simple extension of this criterion was more recently applied to predict the

*e-mail: marcio.andreato@gmail.com best glass-forming compositions. This was shown to lie within fields of mutual and simultaneous topological instability of all the crystalline phases competing with glass formation in binary and ternary systems ${ }^{4-7}$. This extension can be calculated from atomic radii or molar volumes of the compounds with the expression ${ }^{6}$ :

$$
\lambda \tilde{\sim}=\sum x_{i}\left|\frac{V m_{i}}{V m_{0}}-1\right|
$$

where $\chi_{i}$ is the molar fraction of any component element in a given stoichiometric compound (or simple metal); $\mathrm{Vm}_{\mathrm{i}}$ is the molar volume of the solute elements and $\mathrm{Vm}_{0}$ is the molar volume of the compound. The authors point out that the above equation can lead to substantial errors when the packing factors of elements and compounds differ significantly (see Kiminami et al. ${ }^{5}$ for further details). On the other hand, it is worthy to note that, for a good prediction of the GFA, it is necessary to have a full knowledge about the crystalline phases of the system because the results are given as a ranking of the GFA among all compositions in any region of the system.

However, other factors contribute to glass formation besides the $\lambda$ criterion, so the average difference in the alloy's electronegativity is taken into account as an additional criterion. A synergetic effect is assumed between the two criteria. The difference in electronegativity among the elements of an alloy is directly related to its 
formation enthalpy $(\Delta \mathrm{H})$ and its glass stability ${ }^{8,9}$. It is therefore reasonable to assume that the higher the average electronegativity difference among the elements, the higher the glass forming ability ${ }^{6}$. The average electronegativity can be calculated from the atomic fractions of each element ${ }^{6}$ :

$$
\overline{\Delta e}=\sum x_{i} \sum s_{j}\left|e_{i}-e_{j}\right|
$$

where $\overline{\Delta e}$ is the average electronegativity difference; $\chi_{\mathrm{i}}$ is the atomic fraction of each element; $e_{i}$ is the Pauling's electronegativity of a central atom; $e_{j}$ is the electronegativity of each neighbor and $\mathrm{S}_{\mathrm{j}}$ is the surface concentration according to:

$S_{j}=\frac{x_{j}\left(V_{m j}\right)^{2 / 3}}{\sum x_{j}\left(V_{m j}\right)^{2 / 3}}$

where $\chi_{\mathrm{j}}$ is the atomic fraction of each element in the alloy and $\mathrm{V}_{\mathrm{mj}}$ is the molar volume.

Based on this assumption, a plot is built by taking the minimum $\lambda$ parameter calculated for any given composition according to Equation 1, and then this plot is combined with the average electronegativity difference $(\overline{\Delta e})$ according to Equation 2. The plot is thus a simple multiplication of the minimum topological instability and electronegativity criteria. The "peaks" on this map, represented by brighter white regions, express compositions where the topological instability and electronegativity criteria reach a maximum among the surrounding stable phases. Within a given system, the highest peaks are the most probable places for good glass forming ability (see Figure 1).

In this work, making use of the $\lambda_{\text {min }} \times \Delta \mathrm{e}$ GFA map of the Ni-Nb-B ternary system, compositions were evaluated and some compositions indicated as holders of the best GFA were selected. These compositions are located in the same region studied by Aliaga et al. ${ }^{10}$, who used the topological instability criterion combined with the thermodynamic approach $\gamma^{*}$ to select glass former compositions in the $\mathrm{Ni}-\mathrm{Nb}-\mathrm{B}$ ternary system.

\section{Experimental}

The selected compositions were prepared by arc-melting mixtures of pure $\mathrm{Ni}(99.99 \%), \mathrm{Nb}(99,9 \%)$ and $\mathrm{B}(99.9 \%)$ in a Ti-gettered high-purity argon atmosphere. The ingots were remelted several times to ensure chemical homogeneity. Amorphous ribbons were obtained by melt-spinning in a $\mathrm{Cu}$-wheel (200 $\mathrm{mm}$ diameter) rotating at a peripheral velocity of $30 \mathrm{~m} / \mathrm{s}$. Bulk wedges samples with $0.5 \mu \mathrm{m}$ up to $5 \mathrm{~mm}$ in thickness and $40 \mathrm{~mm}$ in length were produced by the conventional copper mold casting method. The ribbons, with a width of $\sim 3 \mathrm{~mm}$ and a thickness of about $35 \mu \mathrm{m}$, and the wedge specimens were characterized by X-ray diffraction (XRD) with $\mathrm{Cu}-\mathrm{K} \alpha$ radiation and scanning electron microscopy (SEM). The thermal stability was evaluated using differential scanning calorimetry (Netzsch 404 DSC) at a heating rate of $0.67 \mathrm{~K} / \mathrm{s}$ under a flowing Ar atmosphere.

\section{Results and Discussions}

As earlier described, the synergic map of topological instability and average electronegativity were computed for the Ni-Nb-B ternary system, as shown in Figure 1. This figure also shows the compositions selected by Aliaga et al. ${ }^{10}$, and it is noted that their compositions are located at regions of the $\lambda_{\min } \times \Delta \mathrm{e}$ map near the highest peaks in the map, which are the most probable regions for good glass-forming ability. Besides, these compositions are located close to the deep eutectic point, so the melting point of the resulting alloy is lowered. Thus, we selected compositions near the $\mathrm{Ni}_{60.14} \mathrm{Nb}_{36.86} \mathrm{~B}_{3}$ composition that showed the best thermal parameters published by Aliaga et al. ${ }^{10}$. As indicated in Figure 1, we selected four compositions to study: $\mathrm{Ni}_{62.0} \mathrm{Nb}_{35.0} \mathrm{~B}_{3} \mathrm{Ni}_{61.0} \mathrm{Nb}_{36.0} \mathrm{~B}_{3}, \mathrm{Ni}_{59.2} \mathrm{Nb}_{37.8} \mathrm{~B}_{3}$ and $\mathrm{Ni}_{58.1} \mathrm{Nb}_{38.9} \mathrm{~B}_{3}$.

Figure 2a shows the DSC thermograms corresponding to the same alloys, obtained at a constant heating rate of $40 \mathrm{~K} / \mathrm{min}$. All the curves are typical of amorphous structure, exhibiting one endothermic peak corresponding to the
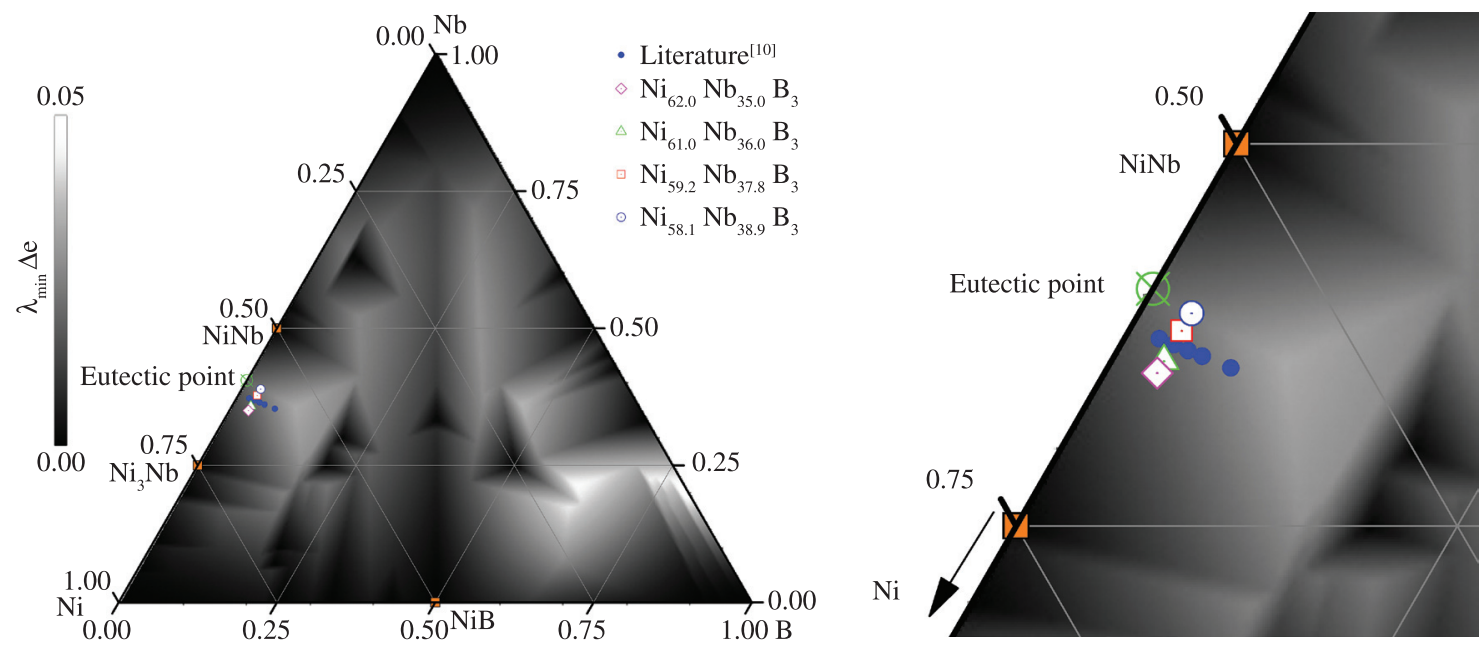

Figure 1. Minimum $\lambda$ and average electronegativity $\left(\lambda_{\min } \times \Delta \mathrm{e}\right)$ map (in gray scale) showing the selected compositions and the compositions studied by Aliaga et al. ${ }^{10}$ 


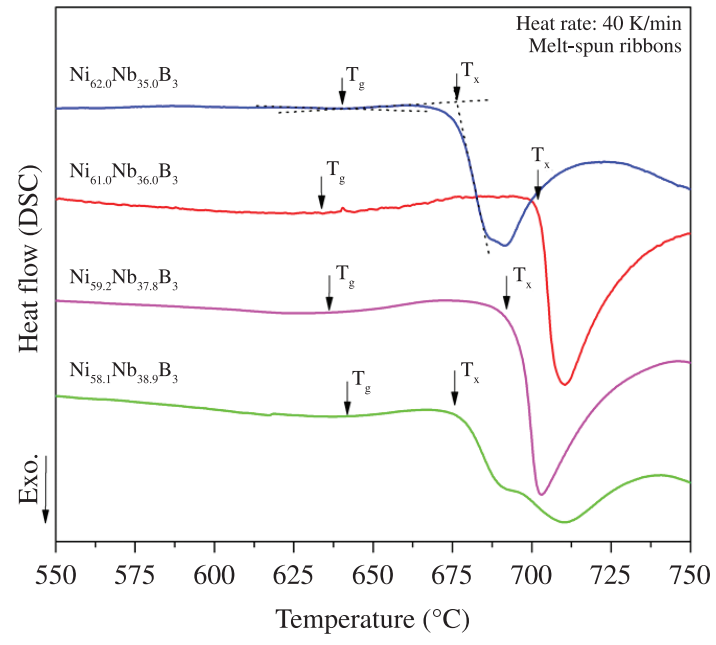

(a)

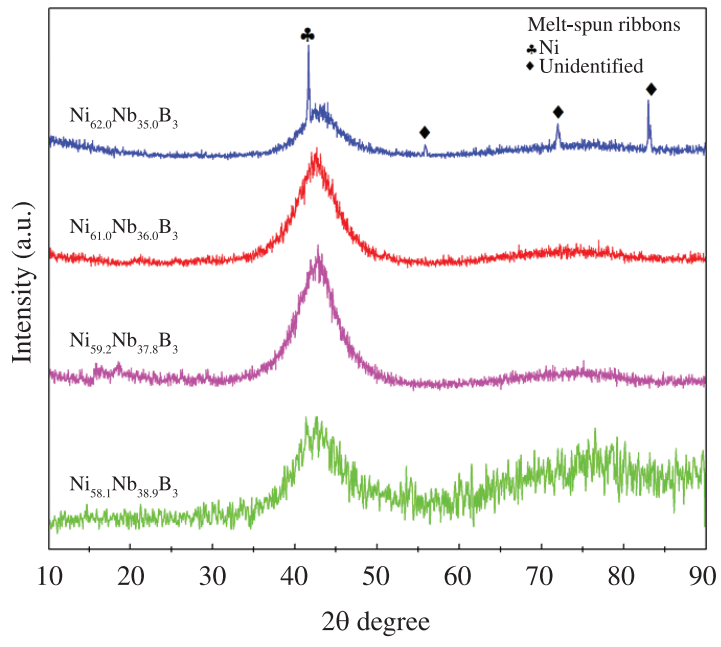

(b)

Figure 2. a) DSC thermograms obtained at a constant heating rate of $40 \mathrm{~K} / \mathrm{min}$ from the Ni-Nb-B alloys; b) XRD patterns of the melt-spun ribbons.

event of glass transition into a supercooled liquid followed by exothermic peaks. Aliaga et al. have observed that the structural transformation into the final phases occurs in different steps with different boron concentrations. This transformation is not so clear in our work because of the reduce temperature range used during the measurements. However, in the $\mathrm{Ni}_{58.1} \mathrm{Nb}_{38.9} \mathrm{~B}_{3}$ composition, which is the nearest to the eutectic point, two exothermic events caused by crystallization of the amorphous phase were present. Additionally, this composition showed shallow peak, which is characteristic of complete crystallization involving decomposition into different intermetallic compounds. The maximum supercooled liquid region of $68^{\circ} \mathrm{C}$ was obtained in the $\mathrm{Ni}_{61.0} \mathrm{Nb}_{36.0} \mathrm{~B}_{3}$ alloy, which is larger than that obtained by Aliaga et al. $\left(\Delta \mathrm{T}_{\mathrm{x}}=60^{\circ} \mathrm{C}\right)$. Figure $2 \mathrm{~b}$ shows the XRD patterns obtained from the different compositions in the form of quenched melt-spun ribbons. Alloys with high $\lambda_{\text {min }} \times \Delta \mathrm{e}$ values presented a broad diffuse halo around $2 \theta \approx 42.5^{\circ}$, which are diffraction patterns typical of an amorphous structure. The $\mathrm{Ni}_{62.0} \mathrm{Nb}_{35.0} \mathrm{~B}_{3}$ composition with the lowest value of $\lambda_{\min } \times \Delta \mathrm{e}$ (see Table 1$)$ also presented a diffraction halo typical of an amorphous structure, but with an indication of relatively lower GFA due to the presence of low intensity peaks associated with crystalline phases.

Figure 3 shows the scanning electron micrograph of the transition region of amorphous phase to crystalline phase in a wedge-section. The $\mathrm{Ni}_{58.1} \mathrm{Nb}_{38.9} \mathrm{~B}_{3}$ alloy with the highest value of of $\lambda_{\min } \times \Delta \mathrm{e}$ (see Table 1) shows the best result with a maximum amorphous thickness of $800 \mu \mathrm{m}$. The regions in which crystalline phases appear clearly in $\mathrm{Ni}_{62.0} \mathrm{Nb}_{35.0} \mathrm{~B}_{3}$, $\mathrm{Ni}_{61.0} \mathrm{Nb}_{36.0} \mathrm{~B}_{3}, \mathrm{Ni}_{59.2} \mathrm{Nb}_{37.8} \mathrm{~B}_{3}$, and $\mathrm{Ni}_{58.1} \mathrm{Nb}_{38.9} \mathrm{~B}_{3}$ alloys are $200,600,325$ and $800 \mu \mathrm{m}$ thick, respectively. Figure $4 \mathrm{a}$ shows details of the amorphous tip and Figure $4 \mathrm{c}$ shows crystalline phases such as dentrites in the $\mathrm{Ni}_{58.1} \mathrm{Nb}_{38.9} \mathrm{~B}_{3}$ alloy.

Table 1 summarizes the parameters of supercooled liquid region $\Delta \mathrm{T}_{\mathrm{x}}$, the critical thickness for the wedge specimens $\left(\Delta \mathrm{X}_{\max }\right)$ and the value of $\lambda_{\min } \times \Delta \mathrm{e}$. The onset temperature
Table 1. Thermal parameters of melt-spun ribbons and the critical thickness for the wedge specimens.

\begin{tabular}{lccccc}
\hline Composition & $\begin{array}{c}\mathbf{T}_{g} \\
\left({ }^{\circ} \mathbf{C}\right)\end{array}$ & $\begin{array}{c}\mathbf{T}_{\mathbf{x}} \\
\left({ }^{\circ} \mathbf{C}\right)\end{array}$ & $\begin{array}{c}\Delta \mathbf{T}_{\mathbf{x}} \\
\left({ }^{\circ} \mathbf{C}\right)\end{array}$ & $\begin{array}{c}\Delta \mathbf{X}_{\max } \\
(\boldsymbol{\mu} \mathbf{m})\end{array}$ & $\lambda_{\text {min }} \times \Delta \mathbf{e}$ \\
\hline $\mathrm{Ni}_{62.0} \mathrm{Nb}_{35.0} \mathrm{~B}_{3}$ & 643 & 678 & 35 & 200 & 0.017 \\
$\mathrm{Ni}_{61.0} \mathrm{Nb}_{36.0} \mathrm{~B}_{3}$ & 645 & 702 & 68 & 600 & 0.018 \\
$\mathrm{Ni}_{59.2} \mathrm{Nb}_{37.8} \mathrm{~B}_{3}$ & 639 & 695 & 56 & 325 & 0.021 \\
$\mathrm{Ni}_{58.1} \mathrm{Nb}_{38.9} \mathrm{~B}_{3}$ & 642 & 677 & 35 & 800 & 0.022 \\
\hline
\end{tabular}

of glass transition $\left(\mathrm{T}_{\mathrm{g}}\right)$ and the event of crystallization $\left(\mathrm{T}_{\mathrm{x}}\right)$ were determined using the tangent method. Our experimental results indicate that the $\Delta \mathrm{T}_{\mathrm{x}}$ was enhanced with the increasing of the Ni contents, reaching the highest value in the $\mathrm{Ni}_{61.0} \mathrm{Nb}_{36.0} \mathrm{~B}_{3}$ composition, and for greater increases in $\mathrm{Ni}$ contents there is a decrease of $\Delta \mathrm{T}_{\mathrm{x}}$. However, this composition did not show the maximum amorphous thickness. The maximum amorphous thickness was obtained by the $\mathrm{Ni}_{58.1} \mathrm{Nb}_{38.9} \mathrm{~B}_{3}$ composition with the highest value of $\lambda_{\text {min }} \times \Delta \mathrm{e}$, which validates the use of the criteria here described. On the other hand, this composition showed the lowest value of $\Delta \mathrm{T}_{\mathrm{x}}$, which would indicate the lowest glass forming ability ${ }^{11}$. Therefore, the use of $\lambda_{\text {min }} \times \Delta \mathrm{e}$ criteria has been shown to be suitable for predicting compositions with high glass forming ability in the $\mathrm{Ni}-\mathrm{Nb}-\mathrm{B}$ system.

Compared with the result reported in the literature for the $\mathrm{Ni}_{62} \mathrm{Nb}_{38}$ binary alloys that showed a $\Delta \mathrm{T}_{\mathrm{x}}=40^{\circ} \mathrm{C}$ and BMGs up to $2 \mathrm{~mm}$ in diameter ${ }^{12}$, the addition of boron revealed an increase of $\Delta \mathrm{T}_{\mathrm{x}}$ up to $68^{\circ} \mathrm{C}$, but with a decrease of maximum amorphous thickness. In addition, Aliaga et al. ${ }^{10}$ obtained a BMG with $1 \mathrm{~mm}$ in diameter fully amorphous and $\Delta \mathrm{T}_{\mathrm{x}}=60{ }^{\circ} \mathrm{C}$ for the $\mathrm{Ni}_{60.14} \mathrm{Nb}_{36.86} \mathrm{~B}_{3}$ composition. For this reason, further experiments are required to cast the composition with higher $\lambda_{\text {min }} \times \Delta$ e values into larger sizes to tell their relevant glass forming ability. 


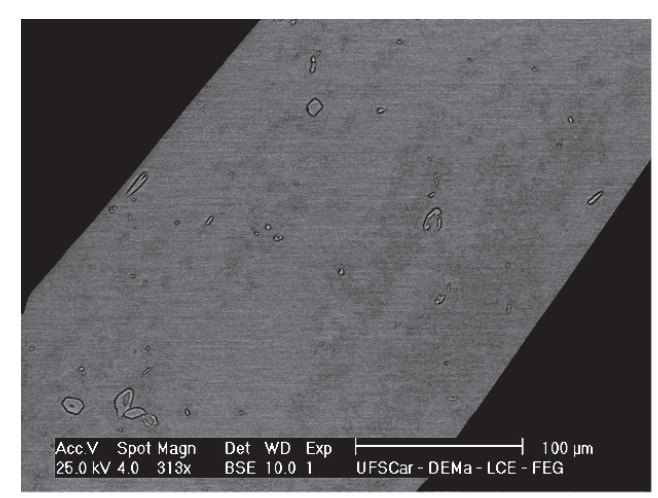

(a)

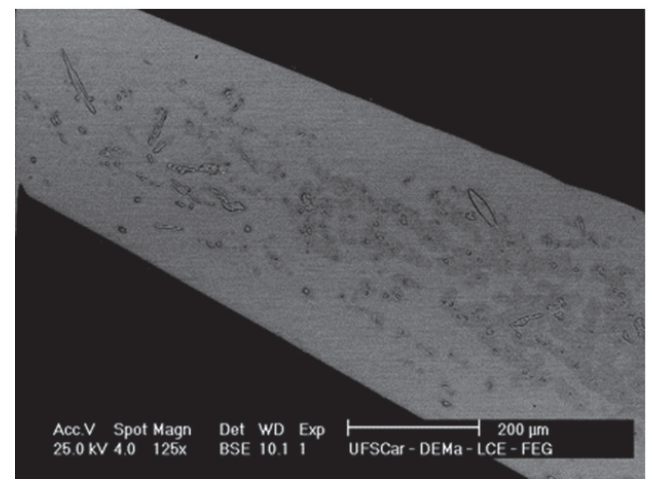

(c)

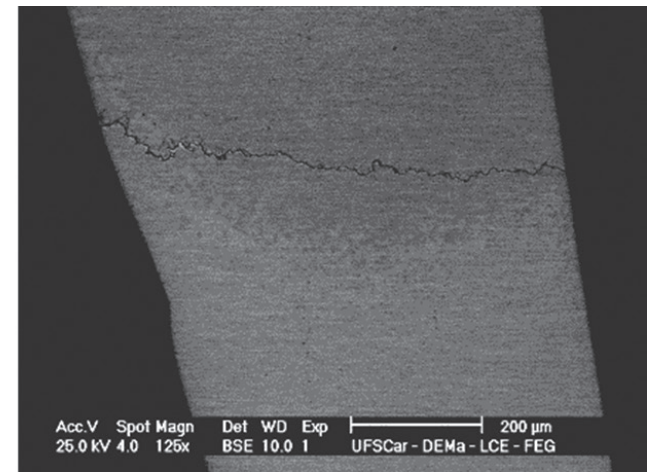

(b)

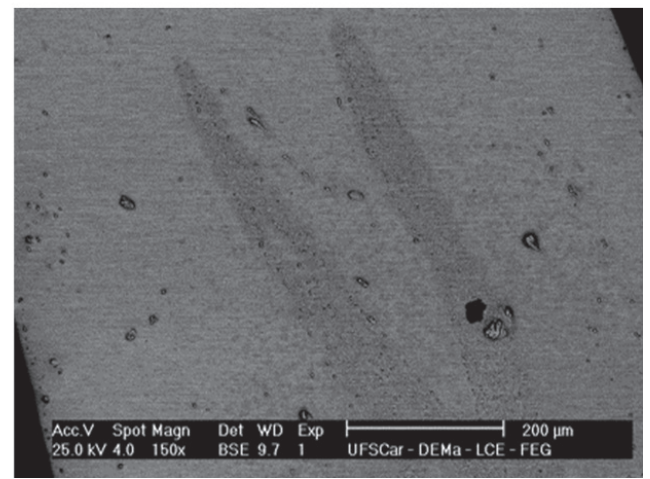

(d)

Figure 3. Scanning electron micrograph (BSE) showing the critical thickness for the wedge specimens: a) $\mathrm{Ni}_{62.0} \mathrm{Nb}_{35.0} \mathrm{~B}_{3}(200 \mu \mathrm{m})$; b) $\left.\left.\mathrm{Ni}_{61.0} \mathrm{Nb}_{36.0} \mathrm{~B}_{3}(600 \mu \mathrm{m}) ; \mathrm{c}\right) \mathrm{Ni}_{59.2} \mathrm{Nb}_{37.8} \mathrm{~B}_{3}(325 \mu \mathrm{m}) ; \mathrm{d}\right) \mathrm{Ni}_{58.1} \mathrm{Nb}_{38.9} \mathrm{~B}_{3}(800 \mu \mathrm{m})$.

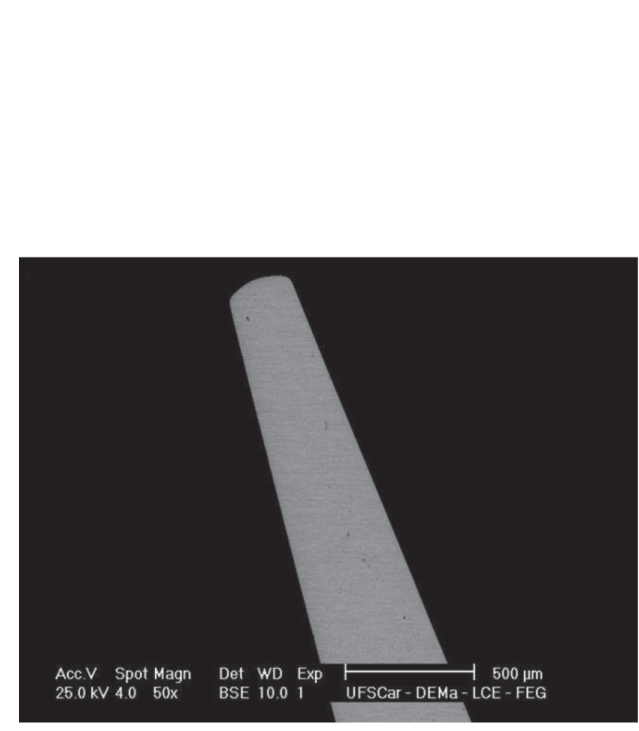

(a)
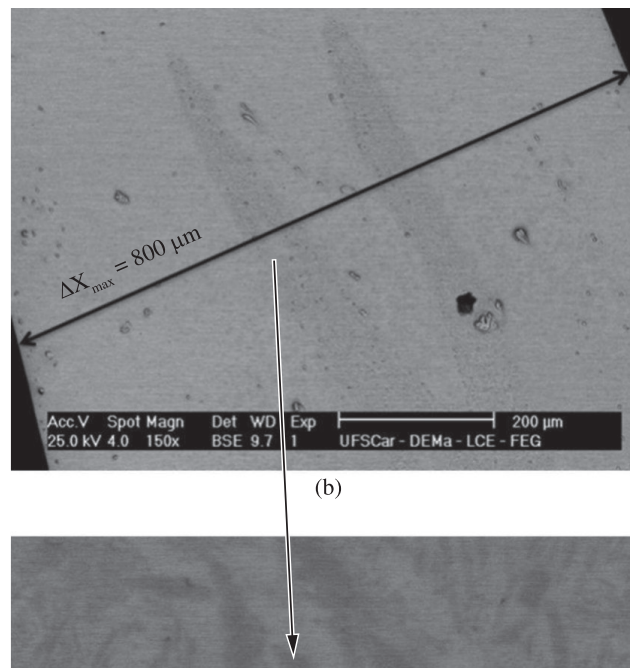

Acc. $V$ Spot Magn Det WD Exp

(c)

Figure 4. Microstructure of $\mathrm{Ni}_{58.1} \mathrm{Nb}_{38.9} \mathrm{~B}_{3}$ alloy: a) amorphous region in wedge-section tip; b) transition region to crystalline phase; and c) detail of the crystalline region. 


\section{Conclusions}

The correlation between the $\lambda_{\min } \times \Delta \mathrm{e}$ criteria and the GFA behaviors in the Ni-Nb-B ternary alloys has been analyzed. The $\mathrm{Ni}_{58.1} \mathrm{Nb}_{38.9} \mathrm{~B}_{3}$ composition showed the better value of the criteria $\left(\lambda_{\min } \times \Delta \mathrm{e}=0.022\right)$ and exhibited the best GFA, with a maximum amorphization thickness in the wedge-section copper mold of about $800 \mu \mathrm{m}$. However, this composition showed the lowest value of $\Delta \mathrm{T}_{\mathrm{x}}$. The highest thermal stability (largest value of $\Delta \mathrm{T}_{\mathrm{x}}$ ) was obtained with the $\mathrm{Ni}_{61.0} \mathrm{Nb}_{36.0} \mathrm{~B}_{3}$ composition $\left(68^{\circ} \mathrm{C}\right)$, which is larger than the value obtained elsewhere ${ }^{10}$. In addition, the results showed a reduction of $\Delta \mathrm{T}_{\mathrm{x}}$ in the composition near the deep eutectic point, however, with a better value of the selection criterion.

\section{References}

1. Inoue A. Stabilization of metallic supercooled liquid and bulk amorphous alloys. Acta Materialia. 2000; 48:279-306. http:// dx.doi.org/10.1016/S1359-6454(99)00300-6

2. Jain SC, Willander M, Narayan J and Overstraeten VR. III-nitrides: Growth, characterization, and properties. Journal of Applied Physics. 2000; 87:965-1006. http://dx.doi. org/10.1063/1.371971

3. Egami $\mathrm{T}$ and Waseda Y. Atomic size effect on the formaility of metallic glasses. Journal of Non-Crystalline Solids. 1984; 64:113-134. http://dx.doi.org/10.1016/00223093(84)90210-2

4. Sá Lisboa RD, Bolfarini C, Botta WJF and Kiminami CS. Topological instability as a criterion for design and selection of aluminum-based glass-former alloys. Applied Physics Letters. 2005; 86:211904. http://dx.doi.org/10.1063/1.1931047

5. Kiminami CS, Sá Lisboa RD, Oliveira MF, Bolfarini C and Botta WJF. Topological Instability as a Criterion for Design and Selection of Easy Glass-Former Compositions in $\mathrm{Cu}-\mathrm{Zr}$ Based Systems. Materials Transactions. 2007; 48:1739-1742. http://dx.doi.org/10.2320/matertrans.MJ200745

6. Oliveira MF, Pereira FS, Bolfarini C, Kiminami CS and Botta WJF. Topological instability, average electronegativity difference and glass forming ability of amorphous alloys. Intermetallics. 2009; 17:183-185. http://dx.doi.org/10.1016/j. intermet.2008.09.013
It was concluded that the combination of the two criteria provides a practical and effective tool to identify good glass-forming compositions in the $\mathrm{Ni}-\mathrm{Nb}$ - $\mathrm{B}$ ternary system, requiring as input only information that is readily available from phase diagrams and crystallographic handbooks for all crystalline phases.

\section{Acknowledgements}

The authors gratefully acknowledge FAPESP (Fundação de Amparo à Pesquisa do Estado de São Paulo, Brazil) for its financial support of this work.

7. Aliaga LCR, Kiminami CS, De Oliveira MF, Bolfarini C and Botta WJF. Selection of good glass former compositions in Ni-Ti system using a combination of topological instability and thermodynamic criteria. Journal of Non-Crystalline Solids. 2008; 354:1932-1935. http://dx.doi.org/10.1016/j. jnoncrysol.2007.10.018

8. Fang SS, Zhou ZQ, Zhang JL, Yao M, Feng F and Northwood DO. Two mathematical models for the hydrogen storage properties of AB2 type alloys. Journal of Alloys and Compounds.1999; 293-295:10-13. http://dx.doi.org/10.1016/ S0925-8388(99)00380-1

9. Fang SS, Xiao XS, Xia L, Li WH and Dong Y. Relationship between the widths of supercooled liquid regions and bond parameters of Mg-based bulk metallic glasses. Journal of Non-Crystalline Solids. 2003; 321:120-125. http://dx.doi. org/10.1016/S0022-3093(03)00155-8

10. Aliaga LCR, De Oliveira MF, Kiminami CS, Bolfarini C and Botta WJF. Selection of glass former compositions in the $\mathrm{Ni}-\mathrm{Nb}-\mathrm{B}$ alloy system. Intermetallis. Submitted to Publication.

11. InoueA,Zhang T and Masumoto T. Glass-forming ability of alloys. Journal of Non-Crystalline Solids. 1993; 156-158:473-480. http://dx.doi.org/10.1016/0022-3093(93)90003-G

12. Xia L, Li WH, Fang SS, Wei BC and Dong YD. Binary Ni-Nb bulk metallic glasses. Journal Of Applied Physics. 2006; 99:026103. http://dx.doi.org/10.1063/1.2158130 